\title{
A ESCRITA NO SÓTÃO DA HISTORIA: LEITURA DE ESCRITOS NA AREIA (2000), DE CARMÉLIA CAVALCANTE GOMES
}

\author{
SIQUEIRA, Joelma Santana ${ }^{1}$ \\ MAGRI, Dirceu ${ }^{2}$
}

RESUMO: Retomando estudos da historiadora Michelle Perrot, sobre os arquivos privados terem sido produzidos por mulheres, e da estudiosa da literatura brasileira Constância Duarte, sobre mulheres escritoras, o objetivo desse texto é realizar uma leitura de poemas de Escritos na areia (2000), livro de Carmélia Cavalcante Gomes, buscando discutir relações entre lírica e sociedade, cientes de que o fundamento de toda lírica individual é uma corrente subterrânea coletiva, consoante o filósofo Theodor Adorno.

PALAVRAS-CHAVE: Memória das mulheres; Lírica e sociedade; Mulheres escritoras.

\section{L'ÉCRITURE DANS LE GRENIER DE L'HISTOIRE : LECTURE DE ESCRITOS NA AREIA (2000), DE CARMÉLIA CAVALCANTE GOMES}

RÉSUMÉ: En reprenant les études de l'historienne Michelle Perrot sur les archives privées produites par des femmes et du spécialiste de la littérature brésilienne Constância Duarte, sur les femmes écrivains, le but de ce texte est de lire les poèmes de Escritos na areia (2000), du livre de Carmélia Cavalcante Gomes, cherchant à discuter des relations entre lyrique et société, conscients que le fondement de toute lyrique individuelle est un courant souterrain collectif, selon le philosofe Theodor Adorno.

\footnotetext{
${ }^{1}$ Doutora pela Universidade de São Paulo - USP e Professora de Literatura Brasileira, Universidade Federal de Viçosa - UFV.

${ }^{2}$ Doutor pela Universidade de São Paulo - USP e Bolsista PNPD, Universidade Federal de Viçosa - UFV.
} 
MOTS-CLÉS : Mémoire des femmes ; Lyrique et société ; Femmes écrivains.

A historiadora Michelle Perrot (1989, p. 11-12), escreveu que, no século XIX, o mundo público considerado importante, principalmente o econômico e o político, estava reservado aos homens, observando-se uma deficiência documental sobre as mulheres. Diferentemente, nos arquivos privados, chamados pela historiadora de "outro sótão da história", as mulheres se exprimiram de forma mais abundante, tendo sido até mesmo "as produtoras desses arquivos, nos casos em que fizeram as vezes de secretárias da família":

Livres de raison [livros de razão] nos quais elas preservam os anais do lar, correspondências familiares cujos escribas habituais são elas, diários íntimos cujo emprego é recomendado às jovens solteiras pelos confessores e, mais tarde, pelos pedagogos, como uma forma de controle sobre si, constituem um refúgio de escritos de mulheres, domínio cuja imensidão tudo atesta. Porém esses arquivos sofrem constante destruição e, somente seus escombros - hoje preservados graças ao fato de seu interesse ter sido finalmente reconhecido nos sugerem sua riqueza! (PERROT, 1989, p. 11).

A destruição desses arquivos por diferentes motivos, incluindo descaso e indiferença alheias, mas, também, vergonha por parte dos familiares e das mulheres que os produziram, é algo comum, razão pela qual Perrot afirma que "como a leitura, a escrita é frequentemente um fruto proibido para as mulheres". Com frequência, "apagam delas mesmas as marcas que adquiriram dos passos que deram no mundo, como se deixá-las transparecer fosse uma ofensa à ordem" (p. 12). Aderindo ao silêncio que a sociedade lhes impõe, consentem "na negação de si que está no âmago das educações femininas, sejam elas religiosas ou laicas, e que a escrita assim como a leitura - contradizem".

Os modos de registro das mulheres, como ressaltou Perrot, "estão ligados a sua condição, ao seu lugar na família e na sociedade". O artigo "Práticas da memória feminina" foi, originalmente, publicado com o título "Théâtres de la Mémoire” na revista Traverses, n. 40, em 1984, e falava sobretudo do século XIX, mas, ao se referir ao modo de rememoração, ao que denominou de "montagem propriamente dita do teatro da memória", destacou que, "pela força das circunstâncias, pelo menos para as mulheres de antigamente, e pelo que resta de antigamente nas mulheres de hoje (o que não é pouco), é uma memória do privado, voltada para 
a família e o íntimo, os quais elas foram de alguma forma delegadas por convenção e posição" (p. 15).

Cabe ressaltar que às mulheres, com frequência, foi imposto o recato, sendo este transmutado em silêncio. O silêncio, cujos ruídos, quando não estrépitos, emergem dos sótãos da memória e das páginas dos livres de raison. A invisibilidade, os momentos vividos à sombra de um pai, depois um marido, a existência apagada, dissolvendo-se entre as idas e vindas dos afazeres domésticos, os salários escassos ou inexistentes, os agradecimentos vagos, o excesso de repreensões e a escassez de elogios, os filhos para criar, a responsabilidade e a culpa antecipada diante de qualquer malogro dos filhos, enfim, a vida doméstica a ser administrada, tudo isso, teve um custo alto às mulheres: sonhos perdidos, aventuras imaginadas, tristezas e alegrias, que, transplantados em prosa ou verso, materializaram-se em textos de modo que o silêncio a que foram submetidas aflora da memória pleno de ruído. Afinal, como a memória não só se opõe ao esquecimento, mas é também um campo de fabulação do passado, na tentativa de esquecer ou apagar traumas pessoais, encontraram na escrita um importante refúgio.

Estudos como os de Perrot articulam-se sobre as memórias privada e coletiva, dado que a exclusão de mulheres dos espaços públicos revelou-se questão fundamental na história das mulheres por muito tempo silenciadas, sem direito a deixar vestígios de suas histórias. Rastros dessa vulnerabilidade social, dos conflitos de representação da alteridade e outros podem ser encontrados nas correspondências, poemas, romances, diários etc. preservados da destruição.

Michelle Perrot, em seu livro Minha história das mulheres (2007, p. 31), reunião de conteúdos apresentados em um programa de rádio transmitido pela Rádio France Culture, sobre os vestígios das mulheres nos arquivos, destaca que "cabe igualmente procurá-los nos materiais impressos e nas bibliotecas" e acrescentou: “"Para ouvir suas vozes - as palavras das mulheres -, é preciso ouvir não somente os livros que falam delas, os romances que contam sobre elas, que as imaginam que as perscrutam - fonte incomparável -, mas também aqueles que elas escreveram". É o que passaremos a fazer agora com a leitura de poemas da obra Escritos na areia, de Carmélia Cavalcante Gomes, cujo título foi extraído do poema "O mar, meu amigo":

Minha mocidade foi toda perdida,

Porque nada aproveitei da vida.

Viver é amar e ser amada,

Eu não fui amada, só magoada.

Hoje me isolo do mundo

E tenho um pesar profundo;

Passar por esta vida e não viver,

É muito pesaroso para qualquer ser. 
O abandono é muito triste.

Quando dentro de nós o amor não existe.

As recordações que tenho são feias.

Procuro escrevê-las nas areias,

Onde uma onda benfazeja as apaga,

Para eu poder esquecer tanta mágoa.

Por isso, gosto e até amo o mar.

É um amigo que me procura consolar,

Mesmo, às vezes, tão violento.

Com ele, quase sempre, encontro alento.

E nas noites de calmaria,

Vou ao encontro dele... esqueço minha agonia.

14/06/83.

Antes de nos determos no poema, consideramos importante retomar o que destacou Theodor Adorno (2003, p. 66), no importante ensaio "Palestra sobre lírica e sociedade", sobre enfrentar a suspeita em torno das relações entre lírica e sociedade quando composições líricas não são "abusivamente tomadas como objeto de demonstração de teses sociológicas, mas sim quando sua referência ao social revela nelas próprias algo de essencial, algo do fundamento de sua qualidade". Como propõe: “a referência ao social, não deve levar para fora da obra de arte, mas sim levar mais fundo para dentro dela. É isso o que se deve esperar, e até a mais simples reflexão caminha nesse sentido".

O poema "O mar, meu amigo", embora composto de uma só estrofe, apresenta rimas emparelhadas (AABB...) que o fazem soar como se fosse composto de dísticos. Nos dez primeiros versos, o sujeito lírico faz um balanço negativo de sua vida com as expressões "toda perdida", "nada aproveitei", "não fui" "não viver" "não existe". Podemos dizer que, até a metade do poema, o sujeito lírico expõe o balanço negativo de sua vida e os motivos a ele associados: ausência do amor, solidão, abandono. Na segunda metade, a partir do décimo primeiro verso, quando anuncia "Minhas recordações são feias"/ "Procuro escrevê-las na areia", o poema assume um tom mais reflexivo e metalinguístico. A partir daqui, o mar passa a fazer parte do poema. Mas, justamente depois de declarar que suas recordações são feias, deparamonos com o par de versos que consideramos mais elaborado do ponto de vista formal: "Onde uma onda benfazeja as apaga/ Para eu poder esquecer tanta mágoa". Esses dois decassílabos de ritmo variado apresentam rimas externas, internas, ricas e imperfeitas. O ritmo parece aludir ao movimento de onda que deságua.

O sujeito poético que tem um pesar "profundo" considera que o mar procura consolá-lo. Seu sentimento pelo mar "às vezes, tão violento" é como uma identificação associada a um 
desejo de potência. Nos dois últimos versos, "E nas noites de calmaria/ Vou ao encontro dele... esqueço minha agonia", este último verso é alongado com as reticências ("Vou ao encontro dele...") antes de realizar a rima imperfeita com a segunda oração "esqueço minha agonia". Propomos que se trata de um encontro imaginário com o mar, de modo que o poema que estamos lendo é seu resultado poético.

Considerar que suas recordações são feias e por isso devem ser escritas onde serão apagadas facilmente é um modo de diminuir a importância de sua lírica, como muitas mulheres diminuíram a importância de seus arquivos, aderindo, como destacou Perrot (1989, p. 12-13), ao silêncio que a sociedade lhes impôs. Isso é compreensível, já que houve muitas dificuldades para as mulheres serem reconhecidas como escritoras, posto que, como escreveram Constância Duarte e Kelen Paiva (2009), no artigo "A mulher de letras: nos rastros de uma história",

Considerando o pressuposto de que o 'homem de letras' é aquele que detém o saber, a mulher encontrou aí um persistente empecilho para seu reconhecimento enquanto intelectual, uma vez que a ela foi negado durante muito tempo o direito à educação. As discussões datam do século XIX, alguns defendiam a educação como forma de libertação da mulher, outros acreditavam que era necessária uma educação voltada à formação moral, uma educação controlada, pois, para ser mãe e esposa virtuosa, a formação do caráter seria mais importante que os conhecimentos instrutivos. Assim, justificava-se uma formação voltada sobretudo às prendas domésticas, ao cuidado do lar e dos filhos, uma 'educação da agulha' que não ameaçasse a estrutura familiar e que não deixasse vago o papel social atribuído à figura feminina: o de mãe e esposa (DUARTE, PAIVA, 2009, p. 11-12).

A obra Escritos na areia é composta de sessenta e seis textos. Os quatro últimos são compostos em prosa, todos dos demais são em verso. Embora haja recorrência de determinados temas como solidão, velhice e amor não correspondido, há também muita variação entre os textos. Nem todos são datados, alguns trazem a indicação de 1983, 1984, 1985, 1986, 1989. O ano mais repetido é o de 1983, quando Carmélia tinha por volta de 63 anos de idade. É recorrente em muitos poemas do volume o tema da irremediável solidão associada à velhice feminina, como nos versos do poema acima "Minha mocidade foi toda perdida/Porque nada aproveitei da vida"; "Hoje me isolo do mundo/ E tenho um pesar profundo". Não há referências a objetos, atividades, realizações etc. $\mathrm{O}$ sujeito poético vive um estado de calmaria que, não à 
toa, rima com agonia no final de "O mar, meu amigo". Essa forma de inércia, porém, é interrompida pela escrita. Vejamos o poema abaixo:

Tentando viver

Voltei aos estudos, para voltar à infância,

Mas nem isso deu certo comigo;

Minha mente voltou à ignorância,

E o tempo, meu maior inimigo

Já não sou o que fui antes:

A inteligência já me falta agora

E a tristeza dos belos instantes

Que um dia tive no outrora.

Vejo as horas passarem,

O pensamento, com preguiça de pensar,

O corpo com pernas que se arrastam

E o olhar com lágrimas a derramar.

Contando nos dedos os dias que se vão,

$\mathrm{O}$ amanhã, que na incerteza fico,

Andando na noite de solidão.

Pensamento com o qual me mortifico.

Ouvindo alguém cantar a vida e o amor,

Espalhando suas tristezas e alegrias

E eu, exprimindo a minha dor,

Nesta manhã nublada e fria.

Monterey, 12/10/1983².

Esse poema, escrito em versos irregulares e com rimas alternadas (ABAB), à primeira vista, aborda uma tentativa de recuperar o tempo perdido com a volta aos estudos, mas, frustrada por causa dos limites impostos pela velhice. Ao tentar estudar, o que poderia ser bom, fazer o sujeito poético voltar à infância, é ruim, pois o faz experimentar o não saber (voltar à ignorância). O verso "Mas nem isso deu certo comigo" exprime um julgamento autodepreciativo. Não é o único. Na próxima estrofe, diz que a inteligência já lhe falta. Nessa segunda estrofe, que antepõe passado e presente, propondo que o sujeito poético e sua inteligência já não são como antes, ocorre uma contradição entre o que enuncia e o que realiza,

\footnotetext{
${ }^{3}$ Em 1983, Carmélia esteve nos Estados Unidos, visitando uma de suas filhas.
} 
pois os dois últimos versos "E a tristeza dos belos instantes"/ "Que um dia tive no outrora", uma frase nominal e uma oração subordinada substantiva só tem o sentido completado pela memória do leitor em relação aos dois versos anteriores, ou seja, pela elipse. No entanto, não deveria ser a alegria dos belos instante que um dia teve no outrora? Ou será que se trata da tristeza de agora pelos belos instantes que um dia teve no outrora? Esse jogo, que interliga passado e presente é bastante perspicaz. O sujeito poético diz que lhe faltam habilidades intelectuais e físicas (pensamento com preguiça de pensar, pernas que se arrastam, olhos que lacrimejam), mas transforma em poesia o pensamento com o qual se mortifica.

O gerúndio, indicando uma ação em curso, está presente no título e nos versos das duas últimas estrofes (contando, andando, ouvindo, espalhando e exprimindo), dando-nos a entender que a tentativa de viver não se restringe à volta aos estudos, diz respeito, também, às ações em curso no dia-a-dia solitário, incluindo a ação de escrever.

Há um momento mais reflexivo no poema com o emprego da metalinguagem no penúltimo verso: "E eu, exprimindo a minha dor". Esse verso, iniciado com a conjunção adversativa "E" parece propor o contraste entre o sujeito poético e outro alguém que ele ouve cantar (“Ouvindo alguém cantar a vida e o amor/ Espalhando suas tristezas e alegrias"), no entanto, o que se observa não é o contraste, mas sim a aproximação entre ambos, principalmente se nos atentarmos para a cadência do poema, quebrada no último verso do poema, com a referência ao instante da escrita, e essa menção ao tempo presente ("Nesta manhã nublada e fria") soa como metáfora da condição física de quem tem o tempo como inimigo ("E o tempo, meu maior inimigo"), mas, também, insere, com o dêitico "nesta", o leitor no tempo da escrita, reinaugurado a cada leitura do poema.

$\mathrm{Na}$ obra, o tema da solidão é recorrente e está presente desde o título de alguns poemas, como "Nem um amigo", "A falta de um amigo" e "Minha amiga solidão". Mas não se trata meramente da solidão de que está fisicamente só. No poema "A falta de um amigo", que inicia com os versos "Não ter um confidente"/ "Faz muita falta ao coração", a solidão é explicada nesses versos: “A solidão não é viver só”/ "Às vezes, estamos numa multidão e...”. Observase em muitos poemas o tom confessional em forma de conversa imaginária, às vezes, mantida com pessoas da convivência familiar. Um poema curioso estabelece um diálogo imaginário a partir de uma canção de Júlio Iglesias, cantor espanhol muito popular no Brasil. Trata-se do poema "Não venho, nem vou (canção que lembra a minha vida)", que traz essa rubrica funcionando como nota preliminar sobre o poema cuja primeira parte reproduz na integra a letra da canção "No Vengo Ni Voy”, gravada em espanhol no álbum Emociones, de 1978, e, em português, no álbum Minhas canções preferidas, de 1981. Após a letra da canção em português, 
segue-se o poema. O sujeito poético parece deixar-se embalar pelo canto romântico, entregando-se ao sonho. Tem-se um diálogo imaginário com uma pessoa que seria um amor idealizado e a esperança de que um dia encontrá-lo. Porém, o poema termina com a quebra da idealização: "Sabendo que não vou alcançá-la neste céu descampado/ E fico a correr os olhos na ânsia de uma longa espera". Se a canção "Não venho, nem vou”, para a autora, lembra sua vida, como está posto na rubrica, os versos que se seguem à canção soam como um registro poético do efeito da canção no sujeito poético.

Adorno (2003, p. 79), antes de demonstrar o modo como diversos graus de uma relação contraditória são expostos por intermédio do sujeito poético no poema "Auf einer Wanderung" (Em uma caminhada), de Mörike, fez questão de esclarecer que "não se trata da pessoa privada do poeta, nem sua psicologia, nem de sua chamada 'posição social', mas do próprio poema, tomado como relógio solar histórico-filosófico". Esperamos poder fazer algo parecido com a leitura do poema "Meus amores":

Aos dez anos, me apaixonei:

Ele era o Adelmo, carinhosamente, Nê.

Um amor inocente, sem tocar nem as mãos,

Mas de que três longos anos viveu.

Depois, um dia saiu da cidade e nem sei

Como suportei tanta saudade dele.

Mas o tempo passou e esqueci essa ilusão,

Aos quatorze, conheci Jairo e, aos poucos,

Nosso amor foi crescendo, crescendo...

E, na avenida à beira-mar, era o nosso encontro.

Mas os estudos e o nosso tempo pouco

Foi nos afastando um do outro e morrendo

Um amor que nunca beijou o outro.

E mais uma vez, prendi no peito o meu sufoco.

Aos dezesseis, fui cortejada insistentemente

Por um colega de meu futuro cunhado.

Logo, em pouco tempo, fui noiva e casei.

Uma união da qual covardemente,

Fui escrava do que não havia sonhado.

E longos anos vivi infeliz,

Nas garras de um egoísta senhor

Que a mim só mágoas deixou.

Se não pareço, um dia amei de fato

E hoje não sou, e o que sou,

Por este amor ser transformado em dor.

As palavras são pobres

Para te agradecer. 
Desejo-lhe toda a felicidade do mundo,

Por teres um coração tão nobre,

Que nos faz esquecer.

E, com este amor tão profundo,

As dores que a vida nos dá,

Conseguimos em frente caminhar.

Rio de Janeiro, 10/05/83.

$\mathrm{Na}$ primeira parte do poema, prevalece o tom narrativo, com as coincidências sonoras entre as palavras, responsáveis por algumas rimas internas e externas, sutis, quase imperceptíveis. Observa-se a denúncia de um casamento precoce. Os dois primeiros amores, pueris, são nomeados no poema. O terceiro, não identificado com nome, colega do futuro cunhado, é aquele com quem se casou. A exclusão desse nome contribui para a ambiguidade do sentimento do sujeito poético por esse "egoísta senhor". O jogo entre as rimas internas dos versos ajudam na manutenção dessa mesma ambiguidade. Expliquemos melhor: os versos "E hoje não sou, e o que sou,/ Por este amor ser transformado em dor" trazem uma contradição sobre não ter amado e amar, ser ou não ser, correlacionado à rima entre as palavras amor e dor.

A quebra promovida pela segunda estrofe, introduzindo uma conversa imaginária, agora, com rimas um pouco mais acentuadas, começa com uma avaliação metalinguística "As palavras são pobres" e introduz o "tu" ("Para te agradecer"). Quem é essa pessoa? Será essa pessoa amada e odiada?. A solução para a dor vivida está em esquecer, mas isso se realiza ironicamente no poema com a rima aguda entre dá/ caminhar. Essas duas palavras terminadas com a vogal aberta "a", encerrando um poema em que prevaleceu no final da maioria dos versos as vogais em timbre fechado, soa como uma falsa solução, um arremedo ligeiro apenas para finalizar o poema.

Maria de Fátima Araújo, no artigo "Amor, casamento e sexualidade: velhas e novas configurações", recorrendo às pesquisas de Philippe Airès, escreveu que

as grandes mudanças no casamento, segundo Ariès (1987), se iniciam com a modernidade. A valorização do amor individual, presente na ideologia burguesa, estabelece o casamento por amor, amor-paixão, com predomínio do erotismo na relação conjugal. Esse novo ideal de casamento impõe aos esposos que se amem ou que pareçam se amar e que tenham expectativas a respeito do amor e da felicidade no matrimônio. Essa imposição teve muitas consequências e contradições. Uma delas é que acabou criando uma armadilha para os casais na medida que se acentuaram as 'idealizações' e 
consequentemente os conflitos resultantes da desilusão pelo não atendimento das expectativas (ARAÚJO, 2002, p. 72).

Em "Meus amores", as contradições entre casamento e amor estão na fatura do poema. Nele, o “egoísta senhor” se confunde com o marido, a pessoa amada e o amor de quem o sujeito poético se ressente.

As armadilhas associadas ao casamento /amor foram e, para muitas mulheres brasileiras, ainda são, especialmente, complicadas. No Brasil, as mulheres, mesmo depois de terem conquistado o direito ao voto, em 1932, como destacaram Patrícia Bertolin e Mônica Machado (2018, p. 185), "até 1962, para trabalhar, precisavam da autorização de seus maridos e tal autorização era uma benesse, podendo ser retirada a qualquer momento". Foi com a promulgação do Estatuto da Mulher Casada, em 1962, que "a lei retirou as esposas do lugar de incapazes, garantindo assim exercício dos seus direitos civis. Todavia, apenas a partir da Constituição de 1988, a Carta Magna equiparou os sexos e garantiu que, no plano da lei, homens e mulheres sejam iguais em direitos e obrigações” (p. 186). Ao longo de nossa história, até a promulgação da atual Constituição, como destacou Salete Maria da Silva (2012, p. 61), "as leis no Brasil (tanto as constitucionais como as infraconstitucionais), sempre tiveram um caráter androcêntrico, quando não flagrantemente machista, reforçando preconceitos e gerando discriminações contra as mulheres". Lembremos, então que o divórcio só foi aprovado em lei em 1977, em plena ditadura militar, e a criminalização do adultério, imputado mais facilmente às mulheres, só foi revogada na lei $\mathrm{n}^{\mathrm{0}}$ 11.106/05, de março de 2005. Nesse contexto social, difícil muitas mulheres não terem vivido como "natural" a dominação do masculino sobre o feminino, quando se trata de algo estrutural.

No próximo poema, deparamo-nos com o tema da solidão e da perda si:

Pedindo a Deus

Na rua, o barulho dos carros em movimento.

Dentro de casa, o silêncio da solidão.

Cabeça girando, envolta nos pensamentos

Dos que foram e dos que nunca virão

Música saindo de um rádio,

Alegria constante de quem canta,

Minh 'alma perdida dentro de um estádio,

Sem um coro de vozes que se levanta. 
Corpo inerte e sem coragem,

Boca de beijo cálido e frio,

Planta sem viço e sem folhagem

Pêlos eriçados de tanto arrepio.

Vida vazia, mas que tanto já deu

Alegrias morrendo dentro de mim

E me perguntando: quem sou eu?

Que faço da vida o meu fim.

Senhor! Tira-me essa angustia louca,

Deixa meu espírito vagar em paz,

Faz calar as queixas em minha boca

E esquecer o tempo que ficou atrás.

Rio, 13/12/83.

O poema parte do espaço físico, o de fora e o de dentro de casa, a partir das referências ao barulho (dos carros) e ao silêncio (da casa). Já aqui podemos pensar na metáfora do dentro e do fora do eu, reforçada na próxima estrofe "Minh'alma perdida dentro de um estádio/ Sem coro de vozes que se levanta". A solidão é acrescida da sensação de esfacelamento: "Corpo inerte", "planta sem viço", "vida vazia” até o total alheamento de si: "quem sou eu?”. O sujeito poético encerra o poema pedindo a Deus que a livre de pensamentos considerados 'angustia louca', como quem pede por uma resignação. Chamar de "angustia louca" aos pensamentos que tem é comparável à depreciação que fez em outro poema quando disse que suas "recordações são feias".

Uma questão que perpassa como uma corrente subterrânea coletiva os poemas até aqui apresentados relaciona-se à condição da mulher idosa em uma sociedade que, como escreveu Marina Maluf e Maria Lúcia Mott (1998, p. 373), baseando-se na crença de uma natureza feminina, que dotaria a mulher biologicamente para desempenhar as funções da esfera privada, produziu o discurso bastante conhecido de que "o lugar da mulher é o lar, e sua função consiste em casar, gerar filhos para a pátria e plasmar o caráter dos cidadãos de amanhã”. Como informa as autoras, "vários preceitos do Código Civil de 1916 sacramentavam a inferioridade da mulher casada ao marido" (p. 375). Esse código "interpretou o modo como cada um dos cônjuges deveria ser apresentado socialmente [...] Ao marido cabia promover a manutenção da família, à mulher restava a identidade social como esposa e mãe. A ele, a identidade pública; a ela, a doméstica" (p. 379). Entre outras consequências, a separação entre as esferas da mulher, restrita ao lar, e do homem, ao espaço público, "ocultou a importância social e econômica prestada pelas mulheres dentro de casa" e 
Perversamente, acabou também por circunscrever a família ao 'lar feliz', onde a mulher é apresentada como rainha, escamoteando-se, assim, o drama da história, os conflitos, as diferenças e as relações de poder que se dão no seu interior, e atribuindo-se às mulheres, sobretudo às casadas, uma importância social como forma de indenização, já que as portas de acesso à igualdade de direitos com os homens foram cuidadosamente fechadas (MALUF, MOTT, 1998, p. 421).

Na penúltima estrofe do poema "Pedindo a Deus", composta pelos versos "Vida vazia, mas que tanto já deu"/ "Alegrias morrendo dentro de mim" / "E me perguntando: quem sou eu?" / "Que faço da vida o meu fim", observamos que a solidão da casa, depois da perda desse papel de mãe cuidadora, faz avultar o eu e a possibilidade de pensar em si mesmo. Infelizmente, essa parece uma experiência mais estranha do que positiva para o sujeito poético.

A irremediável solidão a que todos estão sujeitos é um importante tema dos poemas de Escritos na areia, a que se juntam outros relacionados à condição da mulher em uma sociedade patriarcal, que a circunscreve ao espaço doméstico como único lugar de ser e estar no mundo. A leitura dos poemas de Carmélia permite-nos ler a contrapelo a situação em que muitas mulheres foram colocadas, uma vez que neles a voz que fala é a da mulher que tem angústias, tristezas, críticas, queixas, sentimentos, sonhos, desejos e capacidade de transformar seus pensamentos em poesia. Lendo-os, percebemos ao que Adorno (2003, p. 75) se refere ao tratar da "relação real entre indivíduo e sociedade", qual seja, "não apenas o indivíduo é socialmente mediado em si mesmo, não apenas seus conteúdos são sempre, ao mesmo tempo, também sociais, mas, inversamente, também a sociedade configura-se e vive apenas em virtude dos indivíduos, dos quais ela é a quintessência [Inbegriff]".

Embora a maioria dos poemas tenha um tom triste e sério, vale a pena destacar o poema abaixo pelo que tom de humor que apresenta:

Senhora dona morte

Não, não me leves ainda!

Não, não me leves agora!

Deixa que eu veja a coisa mais linda,

Que é o raiar da aurora...

Não, eu não quero ir,

Pelo menos antes que eu o veja. 
Guarda a tua faca de ferir

E demores mais com este cortejo.

Não, não apagues os meus sonhos,

Pois foi a única coisa que me restou.

Eu te imploro e até te proponho:

Deixa que eu me iluda ainda com o amor.

Eu te peço: sai de perto de mim!

Quero ainda ouvir o pulsar do coração.

Não, não apresses o meu fim!

Alimenta, por algum tempo, esta minha ilusão.

Senhora dona morte,

Não sejas tão cruel:

Deixa que me arraste à procura da sorte,

Para tirar da boca este gosto de fel.

Rio de Janeiro, 19/05/83.

$\mathrm{O}$ aspecto cômico na conversa com a morte está presente no negaceio. O sujeito poético teimosamente se nega a ir com a morte, pedindo-lhe mais tempo. Primeiro, para poder ver o raiar da aurora; depois, para que possa vê-lo, a pessoa amada, para que possa se iludir "ainda com o amor", e, finalmente, na última estrofe, fala mais firme, pedindo-lhe que a deixe por mais tempo à procura da sorte. Pede para ficar não porque seja feliz, mas pelo contrário. Nesse sentido, é como se pedisse para a morte ser cruel deixando-o ficar. Uma vez que os argumentos em favor da autora e do amor não funcionam, recorre-se à dor. Daí, o verso "Não sejas tão cruel" soa como uma ironia no sentido mais corriqueiro dessa figura de linguagem que é o de dizer uma coisa para significar o oposto. O sujeito poético acaba brincando com morte. E o assunto do poema não é a morte, o medo da morte, mas, mais uma vez, o amor não correspondido, só que, dessa vez, em tom jocoso. O tratamento nominal "Senhora dona" é em si uma ironia, não apenas pelo exagero "senhora" e "dona", mas também pela irreverência com que trata a morte ao longo do poema.

Chegando ao final desse breve texto sobre poemas de uma escritora desconhecida da historiografia literária, destacamos que a estudiosa da literatura produzida por mulheres, Constância Lima Duarte, em artigo publicado em 2009, escreveu que, em meados da década de 1980, quando um grupo de pesquisadoras se reuniu com o objetivo de resgatar escritoras do passado, foi preciso muita determinação, pois não era tarefa fácil identificar muita coisa que estava dispersa, foi necessário realizar um "verdadeiro trabalho de arqueologia literária". Uma 
parte dos resultados dessa pesquisa foi publicada nos dois volumes Escritoras brasileiras do século XIX. Com relação ao conteúdo ali reunido, destacou que havia

de tudo nas páginas destas antologias: desde escritoras que nunca foram mencionadas nas histórias literárias, até outras que, apesar da calorosa recepção de ilustres leitores de seu tempo, como Machado de Assis e Olavo Bilac, também desapareceram excluídas do cânone por uma historiografia e uma crítica de perspectiva masculina, que sistematicamente eliminou as mulheres do cenário das letras. Por intermédio de suas obras - romances, poemas, diários, contos, dramas, comédias, ensaios e crítica literária - as escritoras expressam as emoções, a visão de mundo, além de lúcidas reflexões sobre educação, condição da mulher na sociedade patriarcal, direito ao voto, participação na vida social etc (DUARTE, 2009, p. 11).

A história das mulheres escritoras está permanentemente aberta a novas inclusões e correções. Se os filhos de Carmélia Cavalcante Gomes, que nasceu em Maceió, em 1920, há exatos cem anos, na comemoração de seus 80 anos, em 2000, não tivessem reunido seus escritos no volume Escritos na areia e os oferecido à mãe, amigos e familiares como parte de sua festa de aniversário surpresa, não estaríamos aqui lendo sua lírica. A apresentação que eles escreveram para a obra vale a pena ser retomada aqui, pois diz muito do que discutimos:

Falar da autora não é difícil. Da sua obra, sim. Quem é essa pessoa que fala de solidão, injustiça, ingratidão e também de aspirações e desejos? Esta não é, indubitavelmente, a sua obra-prima; o seu jeito de viver sem perder a esperança, isso sim tem sido o seu exemplo. Digo isso com a segurança de quem a conhece há muitos anos e, ao mesmo tempo, ao ler seus escritos, fica possuído por uma sensação perturbadora de quem, na realidade, nunca a conheceu como devia.

Minha mãe, nossa mãe, avó, bisavó, mulher como tantas outras, ensinadas a não reivindicar, mesmo as aspirações mais simples, desejadas em um momento e esquecidas no instante seguinte, trocadas pelos deveres de um ser criador e formador de caráter.

Mesmo quando o vento parecia querer espalhar os destinos de cada um, colocando-os em lugares distantes um do outro, ali estava o ponto de partida, ligado pelo cordão umbilical que depois virou uma simples linha telefônica, uma tênue figura do que foi durante os anos de proteção, alimentação, 
cuidados, incentivos e preocupações, mas que sempre permitia dizer com saudade: Alô?... Oi mãe, a senhora está bem? Agora nos seus 80 anos, sua descendência pretendeu homenageá-la, sabendo verdadeiramente, no entanto, que é ela que está sendo homenageada com sua intimidade revelada em seus escritos.

Parabéns, D. Carmélia; embora nos sintamos envergonhados por não tê-lo dito de viva voz e muitas vezes como devíamos. NÓS A AMAMOS MUITO!

Carmélia, poeta, teve sete filhos e faleceu em 2003. Pensava que escrevia na areia. Perguntamo-nos o que teria feito a mais em seus poemas se soubesse que seus versos não seriam apagados pelas ondas do mar...

\section{REFERÊNCIAS BIBLIOGRÁFICAS}

ADORNO, Theodor "Palestra sobre lírica e sociedade". In: Notas de literatura I. São Paulo: Duas Cidade, Ed. 34, 2003.

ARAÚJO, Maria de Fátima. “Amor, casamento e sexualidade: velhas e novas configurações”. Psicol. cienc. prof., Brasília, v. 22, n. 2,p. 70-77, June 2002. Available from $<$ http://www.scielo.br/scielo.php?script=sci_arttext\&pid=S1414-

98932002000200009\&lng=en\&nrm=iso>. access $\quad$ on 19 June 2020.https://doi.org/10.1590/S1414-98932002000200009.

BERTOLIN, Patrícia Toma Martins, MACHADO, Mônica Sapucaia. "Cidadania e participação das mulheres: um direito individual ou social?” Rev. direitos fundam. democ., v. 23, n. 3, p. 182-199, set./dez. 2018.

GOMES, Carmélia Cavalcante. Escritos na areia. Rio de Janeiro, 2000.

DUARTE, Lima Constância, PAIVA, Kelen Benfenatti. "A mulher de letras - nos rastros de uma história". Revista Ipotesi. Juiz de Fora, v.1, n.1, jul/dez. 2009. Disponível em $<$ https://www.ufjf.br/revistaipotesi/files/2009/10/a-mulher-de-letras.pdf $>$ Último acesso em 03 mar. 2020.

DUARTE, Constância Lima. “Arquivos de mulheres e mulheres anarquivadas - história de uma história mal contada". Revista Gênero. Niterói, v.9 n.2 sem. 2009.

MALUF, Marina \& MOTT, Maria Lúcia. "Recônditos do mundo feminino". In: NOVAIS, Fernando (org.). História da vida privada no Brasil. Vol 3. São Paulo: Companhia das Letras, 1998.

PERROT, Michelle. "Práticas da memória feminina". Revista Brasileira de História. v. 8, n. 18, São Paulo: ANPUH, Ago. 1989.

Minha história das mulheres. Trad. Angela M. S. Corrêa. São Paulo: Contexto,

2007.

SILVA, Salete Maria da. "Constitucionalização dos direitos da mulher: um desafio da incorporação da perspectiva de gênero no direito". Revista Interfaces Científicas. Direito. 
Aracajú v. 1. n.1. out. 2012. Disponível em < https://core.ac.uk/download/pdf/230413597.pdf $>$ Último acesso em 01 abr. 2020. 